\title{
Exercise echocardiography and single photon emission computed tomography in patients with left anterior descending coronary artery stenosis
}

\author{
Alessandro Salustri, ${ }^{1,2}$ Massimo MA Pozzoli, ${ }^{1}$ Ben Ilmer, ${ }^{1}$ Walter Hermans, ${ }^{1}$ Ambroos EM Reijs, ${ }^{3}$ \\ Johan HC Reiber, ${ }^{1}$ Jos RTC Roelandt ${ }^{1} \&$ Paolo M Fioretti, \\ From the Thoraxcenter, ${ }^{1}$ Division of Cardiology and ${ }^{3}$ Department of Nuclear Medicine, \\ Erasmus University Rotterdam, and the ${ }^{2}$ Interuniversity Cardiology Institute of the Netherlands, NL.
}

Accepted 16 November 1991

Key words: exercise echocardiography; SPECT; coronary artery disease

\begin{abstract}
To compare the diagnostic value of exercise echocardiography and perfusion single photon emission computed tomography (SPECT) in the detection of the presence and the severity of coronary artery disease, we studied 21 patients with isolated stenosis of different degree of the left anterior descending artery. Both echocardiography and SPECT were performed in conjunction with the same symptom-limited bicycle exercise test. Positivity of the test was based on the presence of exercise-induced wall motion abnormalities and transient perfusion defects, respectively. For both tests, an 'ischemic' score was derived, as index of extent and severity of myocardial ischemia. Coronary arteriography was evaluated by caliper.

The agreement between exercise echocardiography and SPECT for the presence of coronary artery disease was $90 \%$; the discordance was due to two patients with positive echocardiography and negative SPECT. A good correlation between ischemic wall motion and perfusion score indices was found $(\mathrm{r}=0.78$, $\mathrm{p}<0.0001$. Moreover, the percent diameter stenosis was well correlated with both ischemic indices $(\mathrm{r}=$ $0.75, \mathrm{p}<0.0001 ; \mathrm{r}=0.67, \mathrm{p}<0.001$, respectively). In patients with a positive test, the mean value of ischemic wall motion score index was higher in patients with a diameter stenosis $\geq 70 \%$ than in patients with a diameter stenosis $<70 \%(0.59 \pm 0.19$ vs $0.29 \pm 0.12, p<0.01)$; a similar trend was found for ischemic perfusion score index ( $0.51 \pm 0.35$ vs $0.27 \pm 0.12$, ns).

The results of this study indicate that in patients with single vessel disease of left anterior descending artery exercise echocardiography and SPECT give the same information on the presence, the extent and the severity of myocardial ischemia.
\end{abstract}

\section{Introduction}

Exercise electrocardiography and myocardial perfusion scintigraphy are the most common non-invasive diagnostic tests in patients with suspected coronary artery disease [1-7]. In the last few years, exercise echocardiography is emerging as a promis- ing alternative for assessing the functional severity of coronary stenoses [8-11]. However, few studies have been addressed to compare the relative diagnostic efficacy of the two imaging tests [12-14]. Furthermore, no study has been designed so far to explore the relation between the results of exercise echocardiography and exercise perfusion scintigra- 
phy (when simultaneously applied) in patients with coronary stenosis of different severity. In most clinical studies, the visual assessment of coronary stenoses has been used as 'gold standard' for assessing the diagnostic efficacy of non-invasive tests.

Accordingly, we wanted to assess the diagnostic value of simultaneous exercise echocardiography and perfusion single photon emission computed tomography (SPECT) in a homogeneous group of patients with isolated left anterior descending coronary artery stenosis, quantitatively assessed.

\section{Study group}

From july 1989 to august 1990, 221 patients primarily referred for perfusion scintigraphy underwent simultaneous exercise echocardiography and SPECT at the Thoraxcenter. From this large group we selected all the patients who fulfilled the following requirements: 1) isolated narrowing limited to the left anterior descending artery on coronary arteriography performed within two weeks of the non invasive test; 2) no ECG evidence of previous transmural myocardial infarction; 3) no previous cardiac surgery; 4) no evidence of cardiomyopathies, congenital or acquired valvular heart disease. Twenty-one patients comprised the study group representing a consecutive series meeting the above requirements; 17 were men and 4 were women. Their mean age ranged from 37 to 77 years (mean $59 \pm 11$ years). Seven patients had a documented previous non- $Q$ wave myocardial infarction. At the time of the tests, betablockers were being taken by 8 patients.

\section{Methods}

All patients underwent a symptom limited upright bicycle ergometry with stepwise increments of 20 Watts each minute. ECG was continuously monitored (leads II, V2, V5) and recorded every minute (12-lead). The level of the ST segment was calculated by a signal averaged computerized system (Cardiovit CSG/12, Schiller). $\mathrm{A} \geq 1 \mathrm{~mm}$ hori- zontal or downsloping ST segment depression occurring $80 \mathrm{msec}$ after the $\mathrm{J}$ point was considered ischemic. Seventeen patients reached an adequate exercise end-point, defined as the development of typical angina pectoris, ischemic ST segment depression, or achievement of $\geq 85 \%$ of their maximal predicted heart rate.

\section{SPECT imaging}

At peak exercise, either $370 \mathrm{MBq}$ of $99 \mathrm{~m}$-Tc-metoxy isobutyl isonitrile (MIBI) $(\mathrm{n}=12)$ or $111 \mathrm{MBq}$ of 201-thallium ( $n=9$ ) was injected in an antecubital vein. Patients continued to exercise for another one to two minutes. Then, the protocol was different, according to the different radiotracer used. When 201-thallium was administered, stress imaging started within 10 minutes of the termination of exercise and redistribution images were acquired 4 hours after the injection. When MIBI was used, stress images were acquired one hour after exercise; for resting studies, patients were reinjected with $370 \mathrm{MBq}$ of MIBI at least 24 hours after the stress studies.

All the images were acquired by a Siemens Gammasonics single head Rota Camera (Orbiter) equipped with 37 photomultiplier tubes, a 3/8 inch Nal crystal and a low-energy, all-purpose collimator. Thirty-two projections were obtained $\left(180^{\circ}\right.$ scanning, from left posterior oblique to right anterior oblique projection) with an acquisition time of $45 \mathrm{sec}$ per projection. The digitizing matrix $(64 \times$ 64 word mode) was selected in the mid portion of the camera image by using a zoom factor $V 2$. Tomographic data were reconstructed with the SPETS package (Nuclear Diagnostic AB, Hagsten, Sweden). The direction of left ventricular long axis was determined from two orthogonal views (anterior and lateral); oblique slices (short axis) and sagittal slices (vertical long axis), perpendicular and parallel to the long axis respectively, were reconstructed. For each patients, six oblique (short axis) slices were defined from the apex to the base, and three sagittal slices from septum to the lateral wall. 
To compare exercise and reperfusion studies, the short axis and the sagittal slices were displayed as pairs and interpreted by the same experienced observer, who was unaware of clinical data, echocardiographic and angiographic results. In our center, simultaneous scintigraphic and echocardiographic studies are always interpreted and scored without knowledge of other data. Each short axis slice was divided into 8 equal-sized regions; the septal part of the two upper slices (4 segments) was not evaluated, since this portion corresponds to the fibrous interventricular septum and may result in reduced uptake. The apical region was evaluated from the three central sagittal cross section, yelding a total of $44+3=47$ segments per patient study. The myocardial uptake of the radiotracer was visually graded for each segment with a 5-point scale $(0=$ normal, $1=$ slightly reduced uptake, $2=$ moderately reduced uptake, $3=$ severely reduced uptake, 4 = 'absence' of uptake). An 'ischemic' response was defined as transient perfusion defects in at least two contiguous segments and/or slices. Perfusion score indices were then calculated by averaging the scores for all segments, both in the post-exercise and in the rest studies. An 'ischemic' perfusion score index was derived by the difference between stress and rest indices, giving an idea on both extent and severity of myocardial ischemia.

\section{Exercise echocardiography}

All echocardiograms were performed by a cardiologist, using either a 3.5 or $2.5 \mathrm{MHz}$ transducer and a commercially available wide angle phased array system (Hewlett Packard, Sonos 1000). Standard parasternal long- and short-axis views and apical two and four chamber views were recorded at rest with the patient in the left lateral position. Multiple apical views, including the apical long-axis view, were used instead of parasternal views when the latter gave poor image quality. After reaching the exercise end point, the patients were immediately placed in the same left lateral position and the stress echocardiograms were obtained in the same four views. The rest and stress images were record- ed on videotape and were also digitized on line using a Nova Microsonics PreVue III system. This system was set up to record at rest one representative cardiac cycle obtained from 4 different views. After exercise, 4 consecutive cardiac cycles for each view were captured; the cycle with the highest image quality was then selected and displayed side-by-side with the corresponding rest cycle. Two different quad-screen formats, showing the rest and stress images, were finally stored in a 5 $1 / 4$ inch double-side high-density floppy disk.

All echocardiograms were reviewed on floppy disk as a continuous loop at different playback speeds by two observers who were unaware of the results of exercise test, scintigraphic data or coronary arteriography. For purpose of analysis, left ventricular wall was divided into 14 segments [15]. Both systolic wall thickening and inward wall motion were visually evaluated; each segment was graded with a 4-point scale ( $1=$ normal, $2=$ hypokinetic, 3 = akinetic, $4=$ dyskinetic). An ischemic response was defined as a wall motion abnormality in one or more segments which were normal at rest, or a worsening of wall motion in one or more segments which were hypokinetic at rest. A wall motion score index was derived, for both rest and stress studies, by dividing the total score by the number of the segments. An 'ischemic' wall motion score index was then calculated from the difference between stress and rest indices. Accordingly, an ischemic score by 0 was associated with no evidence of stress-induced myocardial ischemia. In our laboratory, inter-and intra-observer variability for stress echocardiography has been found to be minimal [14].

\section{Assignment of different left ventricular regions to} specific coronary arteries

To assign the vascular territories of the different coronary arteries, both the 47 segments imaged by SPECT and the 14 segments imaged by echocardiography were combined in the same corresponding ventricular regions, denoted as anterior, posterolateral, inferior, interventricular septum, and 
apex. The interventricular septum and the apex were attributed to the left anterior descending artery distribution; the lateral wall to the left circumflex artery; the inferior wall to the right coronary artery.

\section{Coronary arteriography}

Coronary arteriography was performed using the Judkins technique. Coronary cineangiograms were analyzed with a PC-based coronary analysis system with a manual caliper program in its basic configuration, developed in our center [16]. For this purpose, the cinefilm was mounted on a standard Tagarno $35 \mathrm{CX}$ projector with built-in video camera. A selected cineframe was then converted into vid- eo format, digitized at a resolution of $512 \times 512 \times$ 8 bits and displayed on a video monitor. For calibration, a region-of-interest around the catheter tip was selected with the mouse of the system, magnified two-fold with linear interpolation and displayed on the video monitor for subsequent measurements. Next, the user indicated with the mouse three pairs of points at the sides of the magnified catheter segment. The average value of the measured width expressed in pixels was compared with its true size (in $\mathrm{mm}$ ), resulting in a calibration factor in $\mathrm{mm} / \mathrm{pixel}$. Then, the arterial segment to be analysed was magnified two-fold and linearly interpolated, and the user defined the obstruction and reference diameters. From these absolute values, percent diameter stenosis was calculated.

Table 1. Exercise echocardiography and SPECT with the coronary angiography findings in the study group.

\begin{tabular}{|c|c|c|c|c|c|c|c|c|c|c|c|c|c|c|}
\hline \multirow[t]{2}{*}{$\mathrm{Pt}$} & \multirow[t]{2}{*}{$\mathrm{A} / \mathrm{G}$} & \multirow[t]{2}{*}{ MI } & \multirow[t]{2}{*}{$\mathrm{bB}$} & \multirow[t]{2}{*}{ ANGIO } & \multicolumn{2}{|c|}{$\mathrm{ECHO}$} & \multicolumn{2}{|c|}{ SPECT } & \multicolumn{2}{|c|}{$\begin{array}{l}\text { ISCHEMIC } \\
\text { INDICES }\end{array}$} & \multicolumn{3}{|c|}{$\begin{array}{l}\text { EXERCISE } \\
\text { TESTING }\end{array}$} & \multirow[t]{2}{*}{ RADIOTRACER } \\
\hline & & & & & rest & stress & rest & stress & echo & spect & ap & st & end-point & \\
\hline 1) & $56 / \mathrm{M}$ & + & + & $100 \%$ & - & LAD & - & $\mathrm{LAD}$ & .71 & .80 & - & + & + & MIBI \\
\hline 2) & $40 / \mathrm{M}$ & - & - & $100 \%$ & - & LAD & - & LAD & .35 & .34 & - & + & + & MIBI \\
\hline 3) & $49 / \mathrm{M}$ & + & + & $80 \%$ & - & $\mathrm{LAD}$ & - & LAD & .42 & .32 & - & - & + & MIBI \\
\hline 4) & $63 / \mathrm{M}$ & - & + & $77 \%$ & - & LAD & - & LAD & .79 & .34 & + & + & + & 201-TI \\
\hline 5) & $55 / \mathrm{M}$ & + & - & $74 \%$ & - & LAD & - & $\mathrm{LAD}$ & .71 & 1.10 & - & + & + & $201-\mathrm{TI}$ \\
\hline 6) & $77 / \mathrm{M}$ & - & - & $67 \%$ & - & LAD & - & - & .35 & 0 & + & + & + & MIBI \\
\hline 7) & $61 / \mathrm{M}$ & - & - & $65 \%$ & - & $\mathrm{LAD}$ & - & $\mathrm{LAD}$ & .42 & .25 & - & + & + & MIBI \\
\hline 8) & $66 / \mathrm{M}$ & + & + & $64 \%$ & LAD & LAD & LAD & LAD & .35 & .47 & - & + & + & 201-TI \\
\hline 9) & $37 / \mathrm{M}$ & + & - & $61 \%$ & - & LAD & LAD & LAD & .14 & .38 & + & + & + & 201-TI \\
\hline 10) & $43 / \mathrm{M}$ & - & + & $58 \%$ & - & - & - & - & 0 & 0 & - & - & - & $201-\mathrm{TI}$ \\
\hline 11) & $51 / \mathrm{M}$ & + & + & $57 \%$ & - & LAD & $\mathrm{LAD}$ & $\mathrm{LAD}$ & .42 & .17 & - & - & + & 201-TI \\
\hline 12) & $75 / \mathrm{M}$ & - & - & $55 \%$ & LAD & - & LAD & - & 0 & 0 & - & + & + & MIBI \\
\hline 13) & $71 / \mathrm{F}$ & - & - & $54 \%$ & - & $\mathrm{LAD}$ & - & LAD & .14 & .21 & - & + & + & MIBI \\
\hline 14) & $64 / F$ & - & - & $52 \%$ & - & - & - & - & 0 & 0 & + & + & + & 201-TI \\
\hline 15) & $64 / \mathrm{M}$ & + & - & $52 \%$ & LAD & - & LAD & - & 0 & 0 & - & - & + & MIBI \\
\hline 16) & $68 / \mathrm{M}$ & - & - & $49 \%$ & - & LAD & - & $\mathrm{LAD} / \mathrm{RCA}$ & .21 & .17 & + & - & + & MIBI \\
\hline 17) & $64 / \mathrm{M}$ & - & - & $48 \%$ & - & $\mathrm{LAD}$ & - & - & .21 & 0 & - & - & + & MIBI \\
\hline 18) & $44 / F$ & - & + & $48 \%$ & - & - & - & - & 0 & 0 & + & - & - & MIBI \\
\hline 19) & $67 / \mathrm{M}$ & - & - & $47 \%$ & - & - & - & - & 0 & 0 & - & + & + & MIBI \\
\hline 20) & $61 / \mathrm{M}$ & - & + & $40 \%$ & - & - & - & - & 0 & 0 & - & - & - & $201-\mathrm{TI}$ \\
\hline 21) & $65 / \mathrm{F}$ & - & - & $37 \%$ & - & - & - & - & 0 & 0 & + & - & - & 201-TI \\
\hline
\end{tabular}

$\mathrm{A} / \mathrm{G}=$ Age/gender $; \mathrm{MI}=$ previous non-Q wave myocardial infarction; $\mathrm{bB}=$ betablocker therapy; Angio = percent diameter stenosis on coronary arteriography; ap = angina pectoris, $\mathrm{st}=$ ischemic ST segment changes; end-point $=$ achievement of an adequate end-point.

The results of exercise echocardiography and SPECT are expressed as specific coronary arteries attributed to wall motion abnormalities or perfusion defects. $\mathrm{LAD}=$ left anterior descending artery; $\mathrm{RCA}=$ right coronary artery. 


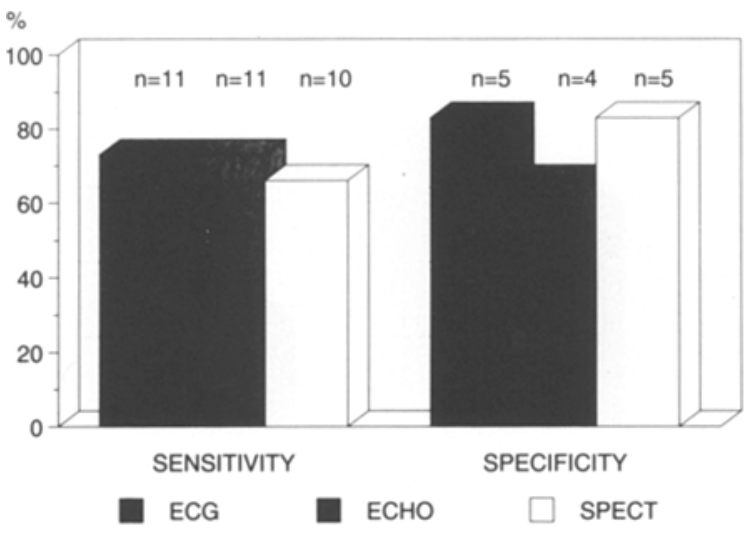

Fig. 1. Sensitivity and specificity of exercise ECG, echocardiography (ECHO) and SPECT for the detection of left anterior descending coronary artery disease (diameter stenosis $\geq 50 \%$ ). Numbers on the top of the bars represent absolute values.

\section{Results}

Some clinical data, the results of exercise ECG, echocardiography and SPECT, and the findings on coronary arteriography are reported in Table 1.

Sensitivity and specificity of exercise ECG, echocardiography and SPECT for the diagnosis of coronary artery disease (defined as \% diameter stenosis $\geq 50$ ) are represented in Fig. 1 . ST segment depression was present in 11 patients with and in 1 patient without coronary artery disease. Transient wall motion abnormalities were detected in 13 patients; in 11 of them a diameter stenosis $\geq 50 \%$ was found. The other two patients had a diameter stenosis of $49 \%$ and $48 \%$, respectively. All patients with a negative echocardiography had a diameter stenosis $<60 \%$.

Transient scintigraphic perfusion defects were found in 11 patients: ten of them had a diameter stenosis $\geq 50 \%$. The other patients had a diameter stenosis of $49 \%$ and concordant stress induced wall motion abnormalities.

The relation between the results of the tests and the severity of coronary artery disease is shown in Fig. 2. The prevalence of a positive exercise echocardiography or SPECT is related to the degree of the stenosis: all the patients with a diameter stenosis $>70 \%$ had both positive exercise echocardiography and SPECT; in the 10 patients with a diameter stenosis between 50 and $70 \%$, exercise echo-

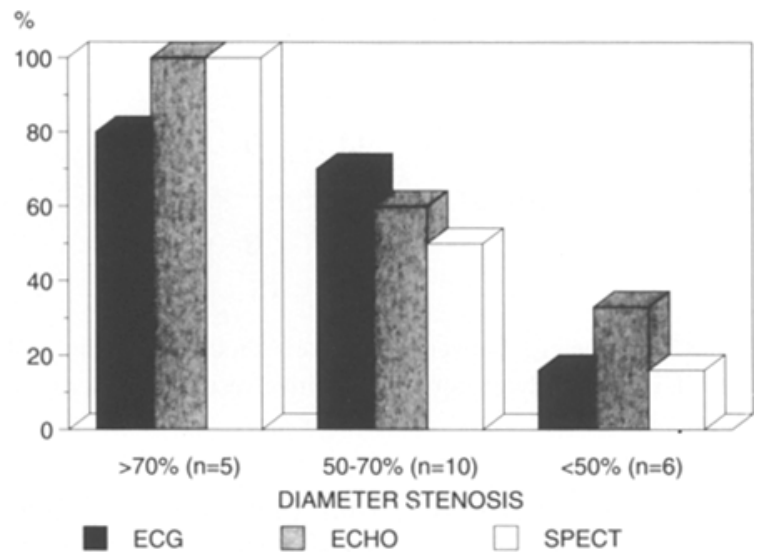

Fig. 2. Prevalence of a positive result on exercise ECG, echocardiography (ECHO) and SPECT according to the different severity of left anterior descending coronary artery stenosis.

cardiography and SPECT were positive in 6 and in 5 patients, respectively; and in the group with a diameter stenosis $<50 \%$, two patients were positive on echocardiography and one patient on SPECT. The incidence of ST segment depression was more 'uniform', while the distribution of angina pectoris during the test was unpredictable.

The agreement between exercise echocardiography and SPECT for the presence of coronary artery disease is represented in Fig. 3. There was an overall good agreement between the two tests (19/ 21 patients, $90 \%$ ). Of the 8 patients with both tests negative, 4 did not achieve an adequate exercise end-point. The disagreement was due to two patients who had a positive exercise echocardiography without transient perfusion defects on SPECT.

Assuming that ischemic score indices represent the amount of myocardium at risk, we compared wall motion and perfusion score indices each other and with the diameter stenosis. Although the different left ventricular wall segmentation and the different score system we used, a good correlation between the two indices was found $(r=.78, p<$ 0.0001 ). Moreover, the \% diameter stenosis was well correlated with both wall motion and perfusion ischemic score indices $(\mathrm{r}=.75, \mathrm{p}<0.0001$; $r=.67, \mathrm{p}<0.001$, respectively).

Among patients with a positive test, ischemic wall motion score index was higher in patients with 


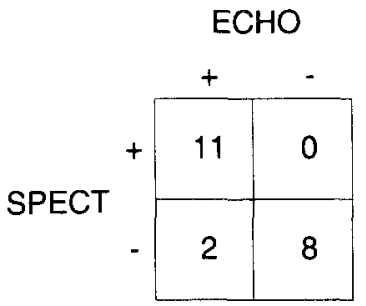

Fig. 3. Agreement between exercise echocardiography and SPECT in the study group. $+=$ positive result; $-=$ negative result.

diameter stenosis $\geq 70 \%$ than in patients with diameter stenosis $<70 \%(0.59 \pm 0.19$ vs $0.29 \pm 0.12$, $\mathrm{p}<0.01)$; a similar trend was found for ischemic perfusion score index, although the difference was not statistically significant $(0.51 \pm 0.35$ vs $0.27 \pm$ 0.12 , ns) (Fig. 4).

\section{Discussion}

The purpose of this study was to compare exercise echocardiography and perfusion SPECT in a group of patients with left anterior descending coronary arterial stenoses. In recent years, exercise echocardiography has been proposed as a feasible and low-cost alternative technique to scintigraphy for the diagnosis of coronary artery disease [8-11]. However, there are very few studies addressing the comparative value of the two tests for the diagnosis of the presence and the severity of coronary artery disease, and in these studies the assessment of coronary arteriograms was limited to a visual judgement [12-14]. We have already compared the results of exercise echocardiography and perfusion SPECT in patients with suspected coronary artery disease and normal ECG at rest [14]; we found a very good agreement between the two tests for the detection of left anterior descending artery stenoses visually evaluated.

The main features of the present study are: a) the homogeneous group of patients with single-vessel disease of proximal or mid left anterior descending artery; 2) exercise echocardiography and SPECT simultaneously performed; 3 ) analysis of coronary lesions by caliper technique.

The results indicate an excellent agreement be-

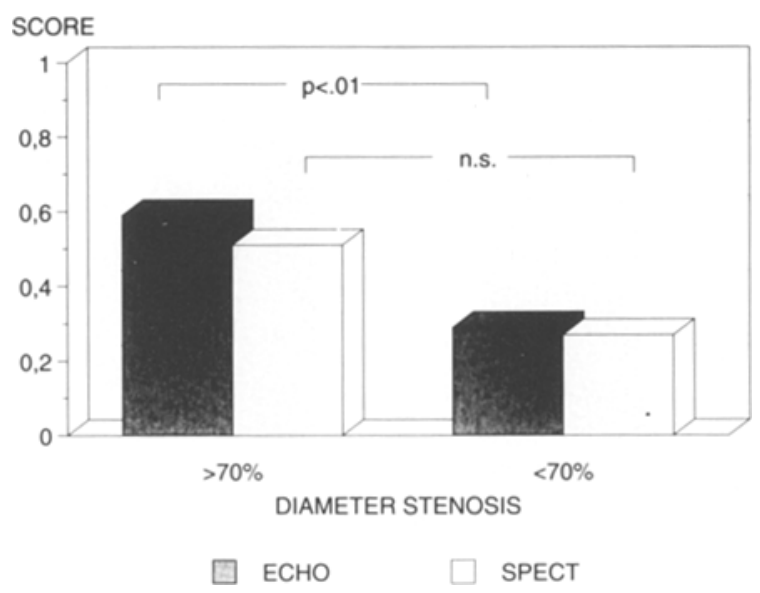

Fig. 4. Mean wall motion (ECHO) and perfusion (SPECT) ischemia score indices in patients with positive test and different degree of coronary artery stenosis.

tween exercise echocardiography and scintigraphy for the diagnosis of the presence of 'significant' coronary disease and for the severity of myocardial ischemia. In particular, analysis of echocardiograms and SPECT showed a more extensive and severe new wall motion abnormalities and transient perfusion defects in patients with diameter stenosis $>70 \%$, compared to patients with less severe stenoses (Fig. 4); however, in the individual patient the score is not helpful to predict the severity of coronary stenosis, due to the considerable overlap of the values.

Consistent with previous scintigraphic and echocardiographic studies [17-20], sensitivity was highest in patients with more severe lesions, of $70 \%$ or more, confirming that the prevalence of an ischemic response is primarily related to the severity of coronary stenosis. Based on our previous experience $[12-14,21]$, these positive results cannot be extended to patients with disease of left circumflex or right coronary artery, in which the sensitivity of exercise echocardiography is slightly lower than that obtained by SPECT.

\section{Limitations of the study}

In this group of patients the usual antianginal therapy was not discontinued; this could affect the as- 
sessment of 'true' sensitivity and specificity of the tests. In particular, 4 of the 8 patients with both tests negative did not reach an adequate exercise end-point, and 3 of them were on betablocker therapy. However, the aim of this study was not to assess the physiologic significance of a coronary stenosis. Rather, we wanted to compare exercise echocardiography an SPECT for the detection of myocardial ischemia in a group of patients primarily referred for perfusion scintigraphy, conditional to their medical treatment.

Another potential limitation of this study is due to the different radiotracers used for SPECT studies. The presence of a 'fixed' perfusion defect on 201-thallium imaging could be due to late redistribution, indicating ischemia rather than scar [22]. This could decrease the prevalence of an ischemic response. In the present study, 3 patients had a fixed defect on 201-thallium SPECT, but all of them had also a reversible defect in the same area. Since positivity of SPECT was based on the presence of reversible defects, these 3 patients were considered positive, independently from the fixed defects.

\section{Clinical implications}

The results of this study suggest that exercise echocardiography and perfusion SPECT give the same information on the presence, the site, the extent and the severity of myocardial ischemia in patients with single vessel disease of the left anterior descending artery. The results of post-exercise echocardiography are strongly dependent on the skill of the operator to record good quality images as soon as possible after termination of exercise. Furthermore, wall motion is the most difficult echocardiographic parameter to evaluate. In the present study, echocardiographic images were interpreted by two observers (because this is the policy in our center); however, the low inter- and intra-observer variability for stress echocardiography in our laboratory indicates that this is not relevant for clinical test utilization, provided a good and long specific training be done. On the other hand, perfusion scintigraphy requires high cost equipment not al- ways readily available. The choice of the 'best' method relies on the facilities available in the institution and on the level of expertise of the individual laboratory.

\section{Acknowledgements}

Alessandro Salustri is supported by the Interuniversity Cardiology Institute of the Netherlands, grant n. 5422 .

Ben Ilmer is supported by the Dutch Heart Foundation, grant NHS 87.079. Massimo Pozzoli is supported by Fondazione Clinica del Lavoro, Centro di Montescano, IRCCS, Pavia, Italy.

\section{References}

1. Bruce RA, Homstein TR. Exercise stress testing in evaluation of patients with ischemic heart disease. Prog Cardiovasc Dis 1969; 11: 371-90.

2. Bodenheimer MM, Banka VS, Fooshee CM, Helfant RH. Comparative sensitivity of the exercise electrocardiogramphy, thallium imaging and stress radionuclide angiography to detect the presence and severity of coronary heart disease. Circulation 1979; 60: 1270-8.

3. Melin JA, Piret LJ, Vanbutsele RJM, Rousseau MF, Cosyns J, Brasseur LA et al. Diagnostic value of exercise electrocardiogram and thallium myocardial scintigraphy in patients without a previous myocardial infarction: a Bayesian approach. Circulation 1981; 63: 1019-24.

4. Ritchie JL, Trobaugh GB, Hamilton GW, Gould KL, Narahara KA, Murray JA et al. Myocardial imaging with thallium-201 at rest and during exercise: comparison with coronary arteriography and resting and stress electrocardiography. Circulation 1977; 56: 66-71.

5. Berman DS, Garcia EV, Maddahi J, Rozanski A. Thallium-201 myocardial perfusion scintigraphy. In: Freeman LM, editor. Freeman and Johnson's Clinical Radionuclide Imaging. 3rd ed. Orlando: Grune and Stratton, 1984: 479537.

6. DePasquale EE, Nody AC, DePuey EG, Garcia EV, Pilcher G, Bredleau Cet al. Quantitative rotational thallium-201 tomography for identifying and localizing coronary artery disease. Circulation 1988; 77: 316-27.

7. Kiat H, Maddahi J, Roy LT, Van Train K, Friedman J, Resser K. Comparison of technetium $99 \mathrm{~m}$ methoxy isobutyl isonitrile and thallium 201 for evaluation of coronary artery disease by planar and tomographic methods. Am Heart J 1989; 117: 1-11.

8. Berberich SN, Zager JRS, Plotnick GD, Fisher ML. A 
practical approach to exercise echocardiography: immediate post-exercise echocardiography. J Am Coll Cardiol 1984; 3: 284-90.

9. Robertson WS, Feigenbaum H, Armstrong WF, Dillon JC, O'Donnel J, McHenry PW. Exercise echocardiography: a clinical practical addition in the evaluation of coronary artery disease. J Am Coll Cardiol 1983; 2: 1085-9l.

10. Armstrong WF, O'Donnel J, Dillon JC, McHenry PL, Morris SN, Feigenbaum H. Complementary value of twodimensional exercise echocardiography to routine treadmill exercise testing. Ann Intern Med 1986; 105: 829-35.

11. Sheikh KH, Bengtson JR, Helmy S, Juarez C, Burgess R, Bashore TM et al. Relation of quantitative coronary lesion measurements to the development of exercise-induced ischemia assessed by exercise echocardiography. J Am Coll Cardiol 1990; 15: 1043-51.

12. Maurer $G$, Nanda NC. Two dimensional echocardiography evaluation of exercise-induced left and right ventricular asynergy: correlation with thallium scanning. Am J Cardiol 1981; 48: 720-7.

13. Heng MK, Simard M, Lake R, Udhoji VH. Exercise twodimensional echocardiography for diagnosis of coronary artery disease. Am J Cardiol 1984; 54: 502-7.

14. Pozzoli MMA, Fioretti PM, Salustri A. Reijs AEM, Roelandt JRTC. Exercise echocardiography and Tc $99 \mathrm{~m}-\mathrm{MIBI}$ single photon emission computed tomography in the detection of coronary artery disease. Am J Cardiol 1991; 67: 350-5.

15. Edwards WD, Taijk AJ, Seward JB. Standardized nomenclature and anatomic basis for regional tomographic analysis of the heart. Mayo Clin Proc 1981; 56: 479-97.

16. Koning G, Reiber JHC, Land CD von, Loois G, Meurs B van. Advantages and limitations of digital calipers in quantitative coronary arteriography. Int J Card Imag 1991; 7(1): 15-30.

17. Nichols AB, Buczek JA, Schwann TA, Esser PD, Blood
DK. Effect of isolated proximal coronary stenotic lesions on distal myocardial perfusion during exercise. J Am Coll Cardiol 1988; 12: 106-13.

18. Harrison DG. White CW, Hivatzka LF, Dort DB, Barnes DH, Eastham CL et al. The value of lesion cross-sectional area determined by quantitative coronary angiography in assessing the physiologic significance of proximal left anterior descending coronary artery stenoses. Circulation 1984; 69: 1111-9.

19. Hadjimiltiades S, Watson R, Hakki A, Heo J, Iskandrian AS. Relation between myocardial thallium-201 kinetics during exercise and quantitative coronary angiography in patients with one vessel coronary artery disease. J Am Coll Cardiol 1989; 13: 1301-8.

20. Wijns W. Serruys PW, Reiber JHC, vd Brand M. Simoons ML. Kooijman CL et al. Quantitative angiography of the left anterior descending coronary artery: correlations with pressure gradient and results of exercise thallium scintigraphy. Circulation 1985; 71: 273-9.

21. Salustri A, Pozzoli MMA, Ilmer B, Reiber JHC, Hermans W. Fioretti PM. Relation of the severity of coronary artery lesions to the development of wall motion and perfusion abnormalities assessed by exercise echocardiography and SPECT [abstract]. Circulation 1990; 82 Suppl III: III-191.

22. Kiat H, Berman DS, Maddahi J, Yang LD, Van Train K, Rozanski A et al. Late reversibility of tomographic myocardial thallium-201 defects: an accurate marker of myocardium viability. J Am Coll Cardiol 1988; 12: 1456-63.

\section{Address for offprints:}

P.M. Fioretti.

Thoraxcenter Ba 300,

Erasmus University Rotterdam,

P.O. Box 1738 ,

300) DR Rotterdam, the Netherlands 